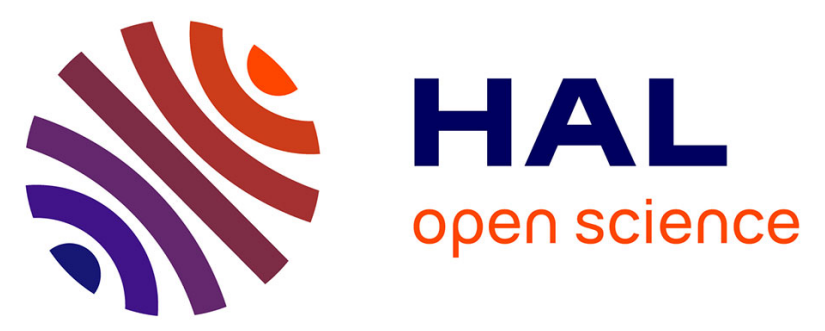

\title{
The Effect of Polymer Properties on the Mechanical Behavior and Morphological Characteristics of Cast Polyethylene Film for Stretch and Cling Film Applications
}

\author{
G. M. Mcnally, C. M. Small, W. R. Murphy, G. Garrett
}

\section{To cite this version:}

G. M. Mcnally, C. M. Small, W. R. Murphy, G. Garrett. The Effect of Polymer Properties on the Mechanical Behavior and Morphological Characteristics of Cast Polyethylene Film for Stretch and Cling Film Applications. Journal of Plastic Film and Sheeting, 2005, 21 (1), pp.39-54. 10.1177/8756087905052804. hal-00572056

\section{HAL Id: hal-00572056 https://hal.science/hal-00572056}

Submitted on 1 Mar 2011

HAL is a multi-disciplinary open access archive for the deposit and dissemination of scientific research documents, whether they are published or not. The documents may come from teaching and research institutions in France or abroad, or from public or private research centers.
L'archive ouverte pluridisciplinaire $\mathbf{H A L}$, est destinée au dépôt et à la diffusion de documents scientifiques de niveau recherche, publiés ou non, émanant des établissements d'enseignement et de recherche français ou étrangers, des laboratoires publics ou privés. 


\title{
The Effect of Polymer Properties on the Mechanical Behavior and Morphological Characteristics of Cast Polyethylene Film for Stretch and Cling Film Applications*
}

\author{
G. M. McNally, ${ }^{\dagger}$ C. M. Small, W. R. Murphy and G. Garrett \\ Polymer Processing Research Centre \\ The Queen's University of Belfast \\ Ashby Building, Stranmillis Road \\ Belfast, BT9 5AH, Northern Ireland
}

\begin{abstract}
Polyethylene films, prepared from a range of mLLDPE, LLDPE, and ULDPE resins containing $4 \%$ polyisobutylene (PIB) from a masterbatch, are manufactured using a Killion cast film extrusion system. FTIR, DSC, and mechanical analysis techniques are used to investigate the effect of comonomer type, density, and melt flow index (MFI) on the mechanical performance, orientation, and crystallinity of these films. The study established that comonomer type and MFI are the greatest factors influencing the mechanical performance and crystallinity. Crystallinity has been found to be the most influential factor governing PIB migration in these films and this in turn is related to polymer type, density, and MFI.
\end{abstract}

KEY WORDS: LLDPE, ULDPE, PIB, cast film, FTIR, DSC, comonomers, octene, hexene, butene, MFI, density, orientation, crystallinity, tear strength, film tack.

\footnotetext{
*This is an extension of a paper presented at ANTEC 2003 in Nashville, Tennessee on May 4-8, 2003; copyright SPE.

${ }^{\dagger}$ Author to whom correspondence should be addressed.
}

Journal of PLASTIC FILM \& SHEETING, Vol. 21—JanUARY 2005 


\section{INTRODUCTION}

DACKAGING FILMS MAKE up a major segment of the polymer industry and polyethylenes are the most common resins used in this application. Linear low-density polyethylenes (LLDPE) and metallocene LLDPE (mLLDPE) are the preferred base materials for the manufacture of thin continuous flat film.

The two most common methods of manufacturing thin polymer films are by blown and cast film extrusion techniques. In cast film manufacture, the polymer is extruded through a slit die and stretched in air, before being cooled rapidly on polished chrome chill rolls. Most, if not all, draw down and molecular orientation occurs in the air gap, the distance traveled between exiting the die and contacting the chill roll. In most commercial processes the air gap is minimized and the haul-off rates are sufficiently high, such that the polymer spends very little time in this melt stretching zone. The orientation effects, which are frozen-in during melt stretching, have been shown to have a major influence on the mechanical behavior, crystallinity, and other key film characteristics. The mechanical behavior of LLDPE and mLLDPE films also make them ideal for cling and stretch wrap film applications; exhibiting high tensile strength, draw down, and enhanced tear and puncture resistance. The creation of an adhesive or tack surface on stretch wrap films is also often desirable in packaging applications and this tack can be achieved by incorporation of polyisobutylene (PIB) as a tackifier agent. The PIB migrates through the bulk polymer to the surface creating the surface tack. This migration will be affected by the morphology developed in the film during manufacture. In our previous investigations [1,2], the effect of PIB concentration and extrusion processing conditions on the diffusion behavior of PIB in a range of LLDPE films was reported. Gulmine et al. [3] suggested that this orientation could be quantified using FTIR spectroscopy and Zhang et al. [4] conducted detailed investigation of orientation on blown films using polarized FTIR techniques. This technique can identify both crystalline and amorphous orientations in films and is an effective means of collecting orientation data rapidly.

\section{The Principles of Polarized FTIR Orientation Analysis}

Infrared active components in polymer film absorb energy from the IR wave, and the transmittance through the film can be measured and analyzed using FTIR spectroscopy. The accuracy of the spectra measured will depend greatly on the choice of scanning parameters, 
as well as film thickness and axis alignment [3,4]. Absorbance peaks at wave numbers 729 and $718 \mathrm{~cm}^{-1}$ in polyethylene have been shown to represent elements within the chain structure whose transition moment has been found to be parallel to the crystalline $a$-axis and $b$-axis, respectively. The orientation in the film is usually expressed as a dichroic ratio (absorbance parallel/absorbance perpendicular); a value of unity suggests isotropic orientation in the film, whilst values deviating from unity infer preferential orientation in one axis. Figure 1(a) shows an FTIR spectrum for LDPE, and the spectrum in Figure 1(b) shows the different contributions in terms of amorphous, $a$-axis, and $b$-axis crystalline phases in LDPE [4]. Machine direction (MD) and transverse direction (TD) orientations can also be quantified using plane polarization of the IR beam, so that the electric vector is aligned parallel

(a)

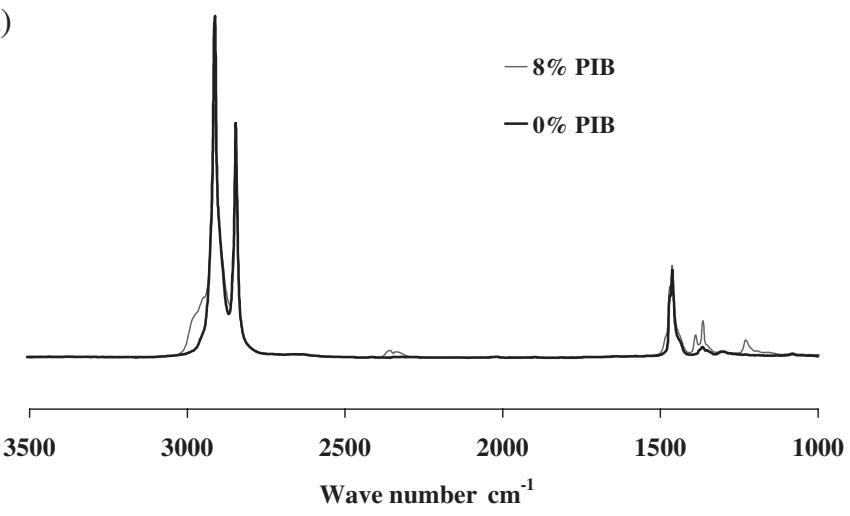

(b)

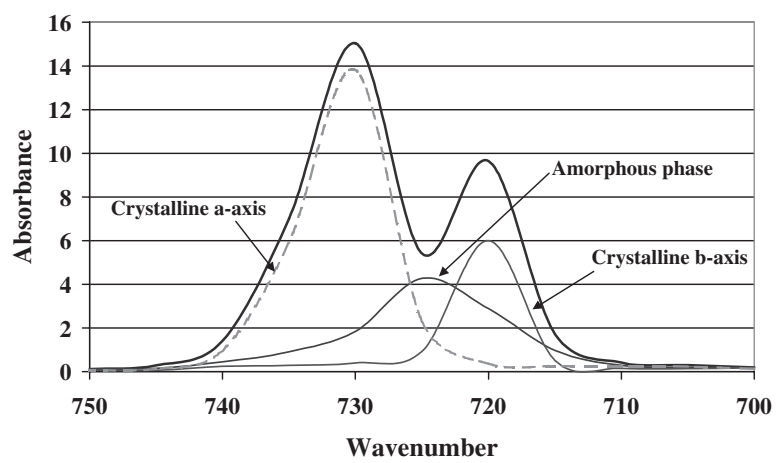

Figure 1. (a) A typical FTIR absorption spectrum for LDPE film (0 and $8 \%$ PIB). (b) Decomposition of polyethylene curve at wavenumbers 718 and $729 \mathrm{~cm}^{-1}$ into $a$-axis, $b$-axis, and amorphous phase contributions. 
or perpendicular to the machine axis. Orientation analysis, using FTIR techniques, carried out by Ajji and co-workers [5,6] and Krishnaswamy and Sukhadia [7] on blown film and biaxially oriented films, showed good correlation of tear resistance with blow-up ratio and haul-off rates.

Unlike the investigations conducted by previous workers, the main aim of the present work was to determine the effects of molecular variables, such as comonomer type, MFI, and density on the mechanical performance, orientation, and crystallinity of thin $(25 \mu \mathrm{m})$ cast polyethylene films. The inclusion of a fixed concentration of PIB (up to 4\%) in the films also permitted investigations of the effects of polymer characteristics on diffusion in LLDPE.

\section{EXPERIMENTAL}

\section{Materials}

The properties of the various LLDPEs used in this investigation are detailed in Table 1. Molecular weights and molecular weight distributions were determined by gel permeation chromatography, conducted by Rapra Technology Ltd. (UK). All blends were produced containing $8 \%$ PIB masterbatch (Polytechs SA), which had $52 \pm 2 \%$ PIB in octene LLDPE $(\rho=0.919, \mathrm{MFI}=1.1)$. The components were mixed thoroughly prior to being fed directly into the feed hopper of the extruder.

\section{Preparation of Films}

Cast films were manufactured on a Killion cast film extrusion system, using a Killion KN150 $38 \mathrm{~mm}$ extruder, with a general-purpose screw

Table 1. Polymer properties.

\begin{tabular}{lccccccc}
\hline Polymer & $\begin{array}{c}\text { Polymer } \\
\text { type }\end{array}$ & $\begin{array}{c}\text { Comonomer } \\
\text { type }\end{array}$ & $\begin{array}{c}\text { Density } \\
\mathbf{( g / \mathbf { c m } ^ { \mathbf { 3 } } )}\end{array}$ & $\begin{array}{c}\text { MFI } \\
(\mathbf{g} / \mathbf{1 0} \mathbf{m i n})\end{array}$ & $\boldsymbol{M}_{\mathbf{w}}$ & $\boldsymbol{M}_{\mathbf{n}}$ & $\begin{array}{c}\text { MWD } \\
\mathbf{( P d})\end{array}$ \\
\hline A & Metallocene & Hexene & 0.918 & 4.5 & 75,400 & 34,300 & 2.2 \\
B & Metallocene & Hexene & 0.918 & 2.5 & 88,000 & 36,000 & 2.5 \\
C & Metallocene & Hexene & 0.918 & 2.5 & 81,300 & 35,900 & 2.3 \\
D & Metallocene & Hexene & 0.918 & 1.1 & 122,500 & 50,100 & 2.4 \\
E & Metallocene & Octene & 0.917 & 4.0 & 85,100 & 26,800 & 3.2 \\
F & LLDPE & Octene & 0.919 & 1.1 & 129,500 & 32,700 & 4.0 \\
G & ULDPE & Octene & 0.903 & 1.5 & 132,500 & 31,900 & 4.1 \\
H & Metallocene & Octene & 0.920 & 0.85 & 130,000 & 39,700 & 3.3 \\
I & Metallocene & Butene & 0.905 & 1.0 & 112,000 & 54,200 & 2.1 \\
\hline
\end{tabular}


$(L / D=30$, compression ratio $=3: 1)$. The temperature profile was ramped from $200^{\circ} \mathrm{C}$ at the feed section to $220^{\circ} \mathrm{C}$ at the die. The extruder was fitted with a $600-\mathrm{mm}$ flexible lip sheet die, with a die gap of $250 \mu \mathrm{m}$. Films were manufactured with an air gap setting of $100 \mathrm{~mm}$ and chill roll temperature of $10^{\circ} \mathrm{C}$. A rubber-coated roller was used to press the hot film extrudate onto the chill roll. The screw speed was held constant at $30 \mathrm{rpm}$. The haul-off ratio and nip roll speeds were adjusted to maintain a constant film thickness of $25 \mu \mathrm{m}$.

At the relatively low extrusion speeds employed, differences in output were insignificant for the range of resins. However, slight differences in draw down ratio were employed so as to account for differences in neck-in and melt strength.

\section{Film Tensile Analysis}

All tensile samples were tested according to ASTM D882-95. Tests were performed using an Instron 4411 Universal Tensile Tester, with a load cell of $0.1 \mathrm{kN}$ and a constant crosshead speed of $500 \mathrm{~mm} / \mathrm{min}$. Samples were tested in both the transverse and machine axes of the film. The tensile strength at break and tensile modulus were recorded.

\section{Differential Scanning Calorimetry}

To investigate the effect of polymer type on the crystalline development of the film, differential scanning calorimetry was used. Tests were performed on all samples using a Perkin-Elmer DSC-6. Samples were heated from 40 to $140^{\circ} \mathrm{C}$ at a rate of $10^{\circ} \mathrm{C} / \mathrm{min}$. The latent heat of fusion, $\Delta H(\mathrm{~J} / \mathrm{g})$, was calculated for each sample.

\section{FTIR Orientation Analysis}

Spectra were obtained using a Perkin-Elmer FTIR spectrometer (Spectrum 1000) fitted with a zinc selenide Graseby Specac $25 \mathrm{~mm}$, ring mounted, wire grid polarizer. The equipment was located in a laboratory maintained at $25 \pm 1{ }^{\circ} \mathrm{C}$. The instrument was operated with a resolution of $2 \mathrm{~cm}^{-1}$ and an accumulation of 128 scans. The IR absorbance scans were analyzed between 710 and $740 \mathrm{~cm}^{-1}$ for changes in the intensity of absorbance peaks with the polarizer gridlines aligned at 0 and $90^{\circ}$ to the MD of the film, i.e., parallel and perpendicular to the MD. Dichroic ratios were calculated for the range of samples. 


\section{Tear Strength Analysis}

All tear samples were tested according to ASTM D1938-94, single-tear method (trouser tear). Tests were performed using an Instron 4411 Universal Tensile Tester, with a load cell of $0.1 \mathrm{kN}$ and a constant crosshead speed of $250 \mathrm{~mm} / \mathrm{min}$. Samples were tested in both the transverse and machine axes of the film and tear propagation strength was recorded.

\section{Film Tack Analysis}

Film samples of dimensions $100 \times 250 \mathrm{~mm}^{2}$, were laid in a double film ply, free from air pockets and film imperfections. Samples were placed between thin metal sheets and a $1 \mathrm{~kg}$ weight was applied to the samples for $24 \mathrm{~h}$ prior to cling analysis. The tack properties of the various films were recorded by measuring the force required to peel these apart at an angle of $180^{\circ}$, as shown in Figure 2 . The tests were performed using an Instron 4411 Universal Tensile Tester at a crosshead speed of $250 \mathrm{~mm} / \mathrm{min}$ and grip length of $50 \mathrm{~mm}$, with a load cell of $0.1 \mathrm{kN}$. Samples were conditioned in an air-circulating oven at 25 and $45^{\circ} \mathrm{C}$ for up to 28 days prior to analysis in order to allow the development of tack. A range of samples were also refrigerated at $-40^{\circ} \mathrm{C}$, to determine the effect of low temperatures on the migration of different molecular weight PIB. Five specimens were analyzed for each film sample, typically the experimental error in results were within $\pm 5 \%$.

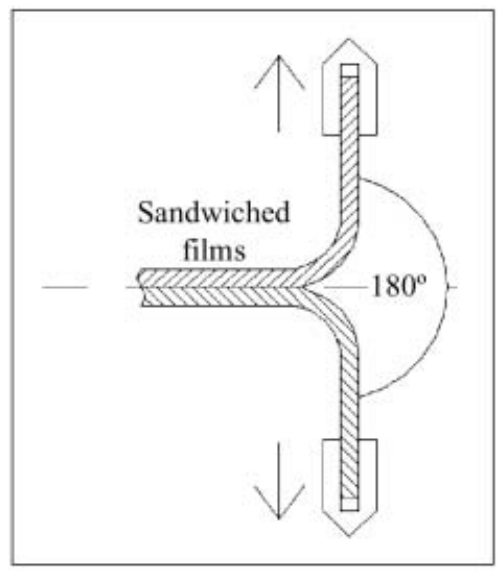

Figure 2. Tack strength analysis. 


\section{RESULTS AND DISCUSSION}

\section{Tensile Properties}

The effect of molecular characteristics on the tensile strength and strain at break of cast films, in both the MD and TD, are shown in Figures 3 and 4. The results show that the MD break strength of the hexene mLLDPE films $\left(\rho=0.918 \mathrm{~g} / \mathrm{cm}^{3}\right)$ decreases progressively with increase in molecular weight $\left(M_{\mathrm{w}}\right)$. This same effect was shown in the octene mLLDPE films, but the decrease was not as significant.

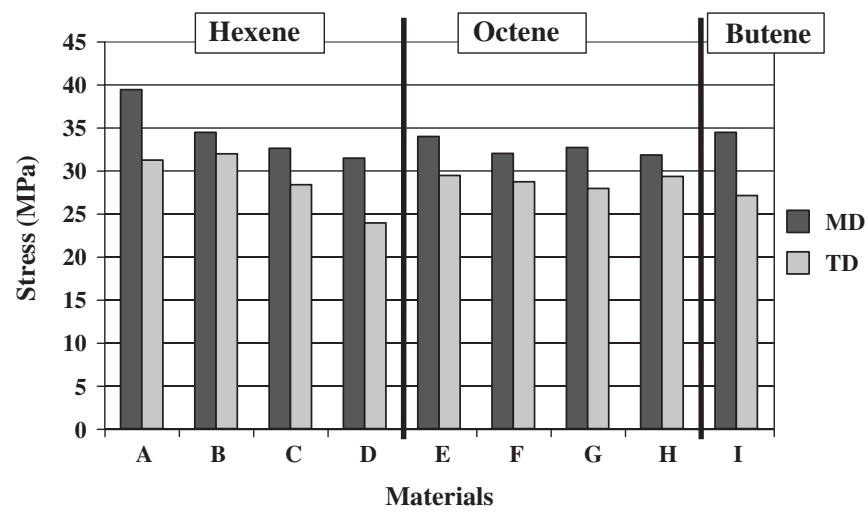

Figure 3. The effect of material properties on MD and TD break strengths.

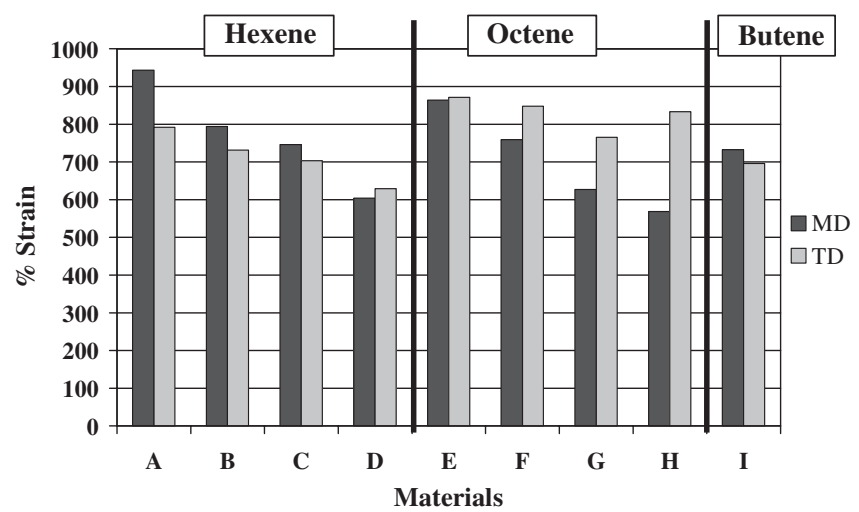

Figure 4. The effect of material properties on MD and TD strains at break. 
There was a similar trend for TD break strength, although the TD strength for all films was significantly lower than MD strength. The results show that increasing $M_{\mathrm{w}}$ caused a progressive decrease in TD break strength in hexene mLLDPEs, with only a slight reduction in TD strength for octene comonomer LLDPEs.

Figure 4 shows the strain at break for the range of films. The pattern of strain versus $M_{\mathrm{w}}$ and comonomer type is similar to that found for break strength. Results show a stepped decrease in strain for films with increasing $M_{\mathrm{w}}$. In general, the values of MD strain were quite similar for films with the same MFI, regardless of comonomer properties; however, the TD elongations recorded were much higher for the octene mLLDPEs.

The effect of molecular characteristics on the tensile moduli for all films is shown in Figure 5. The hexene comonomer films were shown to have significantly lower moduli in both MD and TD compared to the octene films. In hexene films, the MD modulus decreased gradually with increasing $M_{\mathrm{w}}$, and the TD modulus decreased more significantly as the $M_{\mathrm{w}}$ was changed. Higher modulus values were recorded for the octene films and the TD values were higher for the three higher $M_{\mathrm{w}}$ films. The tensile moduli of the butene films were considerably lower than all the other films in both MD and TD.

\section{Crystallinity}

The effect of molecular characteristics on the film crystallinity as determined by $\Delta H(\mathrm{~J} / \mathrm{g})$ is shown in Figure 6 . The hexene mLLDPE films were shown to have considerably higher crystallinities than the

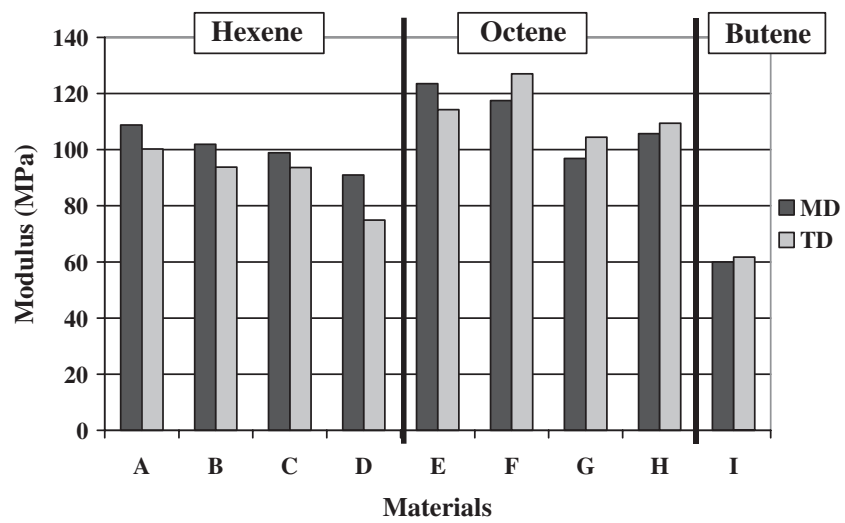

Figure 5. The effect of material properties on MD and TD tensile moduli. 


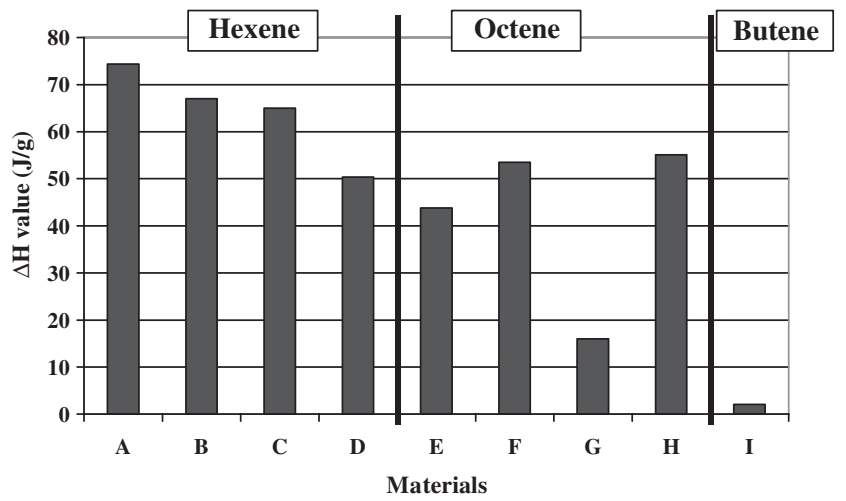

Figure 6. The effect of material properties on film crystallinity.

other films. This can be attributed to the lower MWDs of the hexene comonomer resins, thus a greater proportion of highly crystallizable molecular segments and greater regularity in crystalline structures. Additionally, the reduction in crystallinity as $M_{\mathrm{w}}$ increases for hexene mLLDPE films is supported by previous authors [8-10], who described a general reduction in crystallinity due to increased molecular entanglements, reduced chain mobility, and a lower rate of chain segregation. It has also been observed that film web width decreases with increase in $M_{\mathrm{w}}$, due to increases in extensional viscosity. To achieve a constant film thickness, the line speeds were slightly higher for the higher $M_{\mathrm{w}}$ resins. It is not expected that the differences in residence time alone were sufficient to impart such a significant difference in film crystallinity.

A combination of $M_{\mathrm{w}}$ and density was shown to affect film crystallinity for the octene mLLDPE films and in density generally had a greater effect on crystallinity than $M_{\mathrm{w}}$, as is evident from films $\mathrm{G}$ and $\mathrm{H}$. The increase in crystallinity of octene films as $M_{\mathrm{w}}$ increased, may be attributed to the relatively high MWDs. There is evidence [11] to suggest that the higher proportion of low $M_{\mathrm{w}}$ segments effectively behave as if they increased free volume, i.e., they act as lubricants to larger segments facilitating greater mobility and segregation resulting in higher overall crystallinity.

A very small endotherm was recorded for the butene mLLDPE; this is primarily due to the low density of the resin.

\section{FTIR Orientation Analysis}

Films prepared using the described extrusion conditions showed a change in FTIR spectra, similar to that in Figure 7 (Film F sample), 
when the polarization is changed from 0 to $90^{\circ}$. The effect of molecular characteristics on film orientation as measured by FTIR analysis is shown in Figure 8. The graph shows the dichroic ratio determined from the absorbance peaks of the FTIR scans for the two identified peaks in polyethylene. The hexene mLLDPE films are shown to have a dichroic ratio $\approx 1$ at both 718 and $729 \mathrm{~cm}^{-1}$. This would indicate almost isotropic molecular orientation in the MD and TD film axes. This would tend to signify the presence of a higher web stress during film draw down, which could have developed a preferential $c$-axis alignment with the MD of the film and random alignment of $a$-axis within both ND (normal direction of film) and TD. The assumption of $c$-axis orientation in the MD

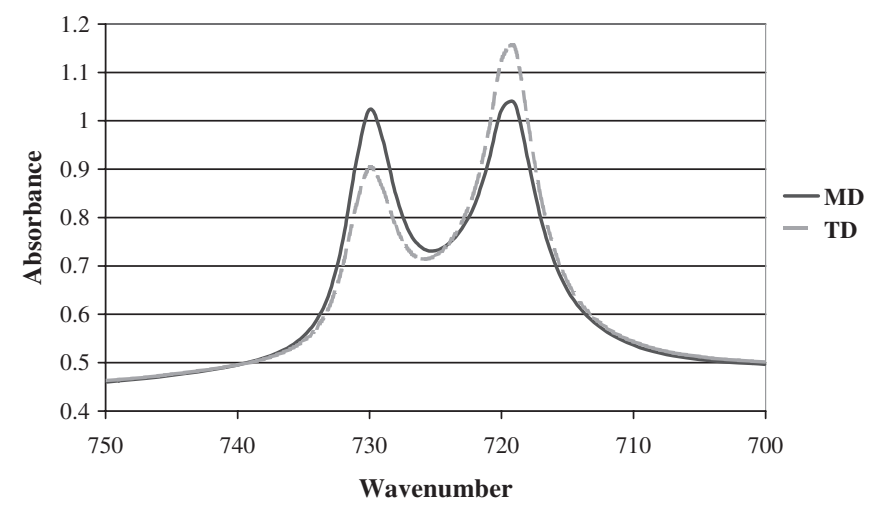

Figure 7. Infrared absorbance scans of MD and TD orientation (polarization 0 and $90^{\circ}$ ).

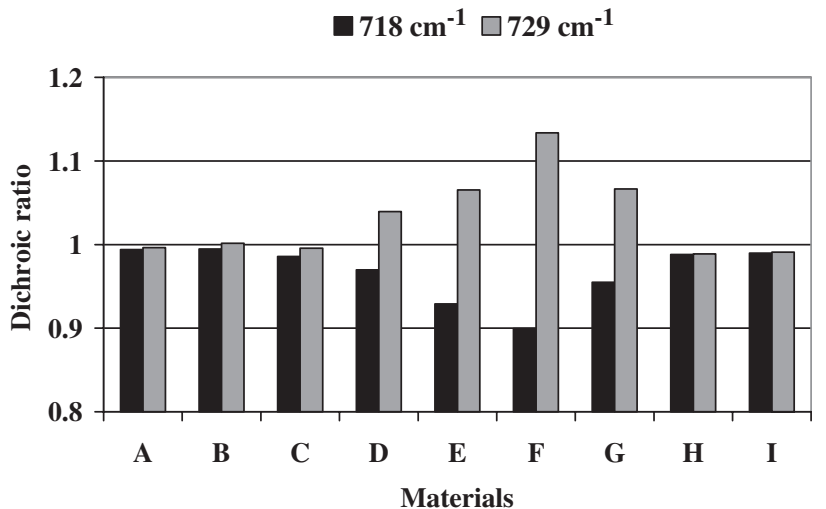

Figure 8. The effect of material properties on orientation characteristics (dichroic ratio). 
would be supported by the higher extensional viscosity (melt strength) and necking-in of the hexene resin films, associated with the molecular architecture of the resins.

The octene comonomer films demonstrated a higher $a$-axis $\left(729 \mathrm{~cm}^{-1}\right)$ orientation in the MD of the film compared to TD. This was accompanied by a similar high $b$-axis orientation in the TD; though it cannot be proved through polarized FTIR analysis, this would infer predominance of $c$-axis orientation in the ND of the film. These results tend to confirm there is a lower stress applied in the melt drawing phase and is supported by extensional viscosity data - the higher MWD of the octene resins results in a lower stressed melt, which encourages a predominance of $a$-axis orientation in the MD.

\section{Tear Properties}

The effect of molecular characteristics on the tear propagation resistance of all films is shown in Figures 9 and 10. In general, film tear strength was higher in the TD compared to the MD. The hexene mLLDPE films showed lower MD and TD tear strengths than the octene films, and in general the tear strength and tear energy decreased with progressive increases in $M_{\mathrm{w}}$ for these films. This confirms earlier work by Ajji and Zhang [5] on LDPE film manufactured by the blown film extrusion process, which reported that tear propagation behavior of these films was closely related to the lamellar arrangement of LDPE film with respect to the MDs and TDs. The TD tear resistance was shown to be proportional to both MD-crystalline $a$-axis and TD-crystalline $b$-axis

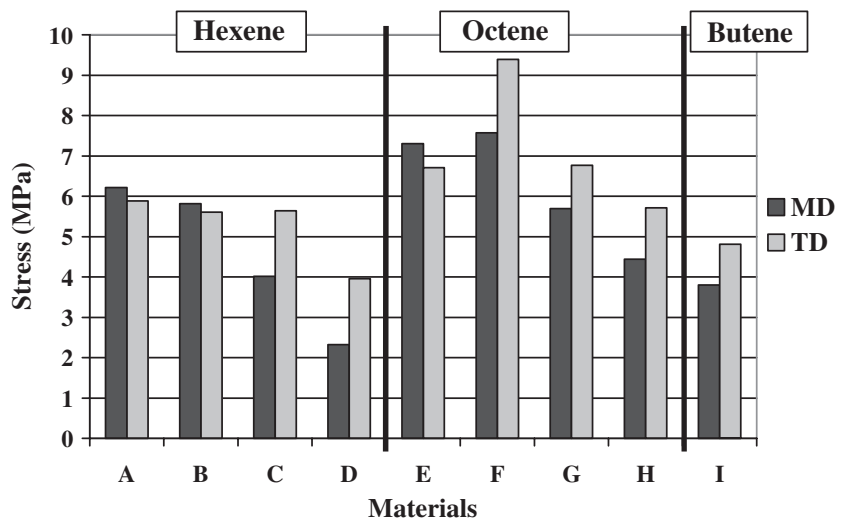

Figure 9. The effect of material properties on MD and TD tear stresses. 


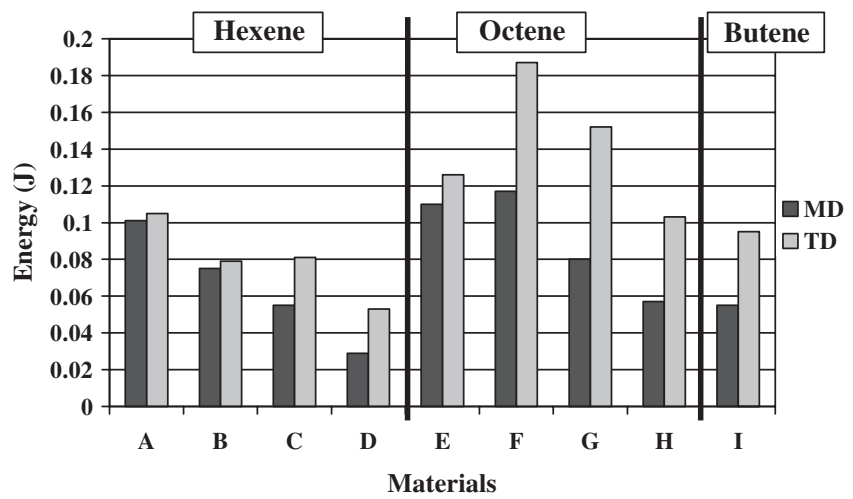

Figure 10. The effect of material properties on MD and TD tear energies.

orientation. As the previous analysis has shown there is no preference for $a$-axis or $b$-axis orientation in the respective axis of the hexene films, this would complement the tear results reported.

The octene comonomer films showed the highest overall tear strengths and in general the tear strength and tear energy was considerably higher in the TD compared to MD. Both MD and TD tear performances of the conventional LLDPE was significantly higher than any of the mLLDPE films; this corresponds with the significantly higher orientation functions observed. This again correlates well to the work by Ajji and Zhang [5] that showed higher $a$-axis orientation along the MD and higher $b$-axis orientation along the TD, leading to higher TD tear resistance.

\section{Tack Strength}

The effect of molecular characteristics on the tack strength of cast films is shown in Figure 11. The migration of PIB from the bulk to the surface of the films was characterized by measuring the tack strength as a function of time, and the results shown are a summary of film tack strength developed after 28 days. It is generally accepted that the main factors affecting diffusion in polymers are: (a) molecular structure of the polymer, (b) crystallinity, and (c) orientation. The hexene mLLDPE films showed a progressive increase in tack strength as the $M_{\mathrm{w}}$ of the resin increased and thus the crystallinity decreased, permitting easier diffusion of the PIB through these more amorphous films. Also, in the hexene films where density remained constant, as the difference between the $M_{\mathrm{w}}$ of the bulk resin and the PIB $M_{\mathrm{w}}$ widens, this increases the incompatibility of the resins and increases the segregation of the blend. 


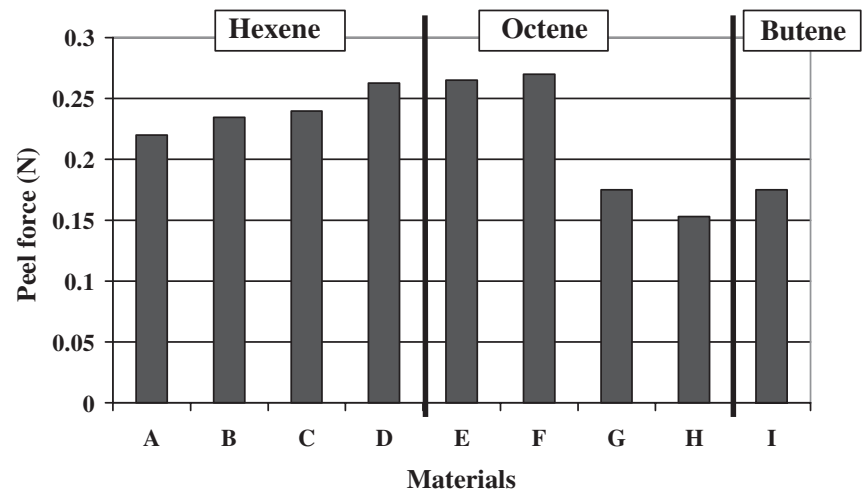

Figure 11. The effect of material properties on film tack behavior (films containing $8 \%$ PIB).

Similar tack strengths were recorded for films D, E, and F (similar density); however the crystallinity (DSC) for octene-based film E was lower than that for D and F. If diffusion were affected solely by the crystallinity it would be expected that film $\mathrm{E}$ would have higher tack strength. However, film $\mathrm{E}$ has a considerably lower $M_{\mathrm{w}}$ than D or F; and the hexene films have shown that migration increased in films manufactured from higher $M_{\mathrm{w}}$ resins. A comparison of tack strengths with FTIR orientation for these films (Figure 8), would also indicate that molecular orientation has less influence on the migration of PIB from the bulk to the surface of films than the inherent resin characteristics, such as density or $M_{\mathrm{w}}$.

Similar trends were recorded for films G and I, where crystallinity was significantly lower and low tack strengths were developed. Interestingly, these films were manufactured from ultra-low density resins. It seems acceptable to assume that the lower structural packing in these resins produces greater free volume, which may reduce the interactions between the bulk polymer and the additive and thus retard the diffusion of PIB to the film's surface. This would tend to suggest that the PIB diffusion process was controlled by a combination of inherent molecular characteristics and structural properties derived from processing.

\section{CONCLUSIONS}

This investigation set out to determine the effect of molecular characteristics on the mechanical performance and the morphological and 
orientation characteristics of a range of LLDPE films manufactured by the cast film extrusion process. This work has shown that the density and molecular weight $\left(M_{\mathrm{w}}\right)$ of polymers has a significant effect on the orientation characteristics of the films, which in turn can be related to the tensile modulus, break strength, and tear resistance of the films. In general, it has been found that crystalline $a$-axis and $b$-axis orientations decreases with progressive reduction in $M_{\mathrm{w}}$. As the orientation function approaches unity, it has been found that the tensile modulus, percentage crystallinity, and tear propagation resistance increase.

The effect of molecular characteristics on film properties is most evident in the tear analysis where the high MWD octenes had much higher tear energy than hexene films. This may relate to the longer chain branch structures in octenes, which would incur higher tear resistance than the shorter chain branching in hexene and butene comonomers. This may also be a combined effect of the bulk molecular architecture, especially the higher molecular weight distributions and lower web stresses.

The studies of PIB tack development have shown that the diffusion process was dependent on a combination of molecular structure, crystallinity, and crystalline orientation.

\section{REFERENCES}

1. Small, C.M., McNally, G.M., Marks, A. and Murphy, W.R. (2002). The Effect of Extrusion Processing Conditions and Polyisobutylene Concentration on the Properties of Polyethylene for Stretch and Cling Film Applications, In: ANTEC Proceedings, pp. 230-234; J. Plas. Film \& Shtg., 18: 245 .

2. Small, C.M., McNally, G.M., Marks, A. and Murphy, W.R. (2002). The Use of FTIR/ATR to Investigate the Migration of Polyisobutylene in Polyethylene for Cling Film Applications, In: ANTEC Proceedings, pp. 2882-2886.

3. Gulmine, J.V., Janissek, P.R., Heise, H.M. and Akcelrud, L. (2002). Polethylene Characterization by FTIR, Polymer Testing, 21: 557-563.

4. Zhang, X., Ajji, A. and Jean-Marie, V. (2001). Processing-Structure-Properties Relationship of Multilayer Films. 1. Structure Characterization, Polymer, 42: 8179-8195.

5. Ajji, A. and Zhang, X. (2002). Correlations Between Orientation and Some Properties of Polymer Films and Sheets, In: ANTEC Proceedings, pp. 1651-1655; J. Plas. Film \& Shtg., 18: 105. 
6. Ajji, A., Auger, J., Huang, J. and Kale, L. (2002). Biaxial Stretching and Structure of Various LLDPE Resins, In: ANTEC Proceedings, pp. 1561-1565.

7. Krishnaswamy, R.K. and Sukhadia, A.M. (2000). Orientation Characteristics of LLDPE Blown Films and their Implications on Elmendorf Tear Performance, Polymer, 41: 9205-9217.

8. Scott Lambert, W. and Phillips, P.J. (1996). Crystallization Kinetics of Fractions of Branched Polythylenes: 2. Effect of Molecular Weight, Polymer, 37(16): 3585-3591.

9. Nishi, M., Hikosaka, M., Toda, A. and Takahashi, M. (1998). Molecular Weight Dependence of Lateral Growth Rate of Polyethylene (1) - An Extended Chain Single Crystal, Polymer, 39(8-9): 1591-1596.

10. Okada, M., Nishi, M., Takahashi, M., Matsuda, H., Toda, A. and Hikosaka, M. (1998). Molecular Weight Dependence of the Lateral Growth of Polyethylene (2) Folded-Chain Crystals, Polymer, 39(19): 4535-4539.

11. Cormia, R.L., Price, F.P. and Turnbull, D. (1962). Kinetics of Crystal Nucleation in Polyethylene, J. Chem. Phys., 37: 1333-1340.

\section{BIOGRAPHIES}

\section{Gerry McNally}

Gerry McNally is a Senior Lecturer in Engineering Materials in the School of Chemical Engineering at the Queen's University of Belfast. He has 12 years industrial experience at the senior management level in polymer extrusion. He is a founder member of the Polymer Processing Research Centre (PPRC) and was made its Director in 2004. His expertise is in various areas of processing of polymers and their additives. He has been, or is, the lead academic supervisor in 15 polymer-related TCS Programs, one of which was awarded Best TCP in 1999. He has published over 175 papers and international conference proceedings.

\section{Christopher Small}

Christopher Small was awarded a BEng (Honours) degree in Mechanical Engineering and a MSc (with distinction) in Polymer Engineering, both from the Queen's University of Belfast. He went on to complete a $\mathrm{PhD}$ in 'Investigating the effects of manufacturing variables 
on the properties and performance of Polyethylene Stretch and Cling films'.

\section{William R. Murphy}

William Murphy is Professor of Chemical Engineering at the Queen's University of Belfast, where he was Head of the Department of Chemical Engineering (1987-1997) and was Director of the Polymer Processing Centre from 1997 to 2004 . He has been active in the research and development of materials processing, including polymers, for over 20 years. He has authored two books and written over 100 papers.

\section{Graham Garrett}

Graham Garrett spent over 20 years working in the textile industry before joining the Extrusion Centre at the Polymer Processing Research Centre at the Queen's University of Belfast, where he is now a process technician. 